\title{
The predatory Atlantic red drum, Sciaenops ocellatus, has invaded the western Taiwanese coast in the Indo-West Pacific
}

\author{
Yun-Chih Liao $\cdot$ Li-Shu Chen $\cdot$ Kwang-Tsao Shao
}

Received: 4 February 2009/Accepted: 9 November 2009/Published online: 20 November 2009

(C) The Author(s) 2009. This article is published with open access at Springerlink.com

\begin{abstract}
The red drums, Sciaenops ocellatus, are predatory marine fish from Atlantic American coast. They were introduced to Taiwan for aquaculture purpose in 1987 and have been reported in the wild along the southwest coast of Taiwan since 1998. Their current distribution is on the western coast of Taiwan and the Matsu Islands of Fujian Province where there are sand and mud bottoms. However, the discontinuous populations of Taiwan and Matsu indicated different sources of introduction. The facts that there are consecutive records of red drums for 7 years including every single month, at multiple localities, and the fish's larger size all point to their survival in the wild. The mechanisms of their introductions are probably the escapes from net cages as well as the deliberate releases to improve fisheries and for religious activities. This paper documents for the first time a marine fish has invaded and established in coastal water off western Taiwan and the Indo-West Pacific. The ecological impact of red drums on the local fish community is still unknown and calls for further studies.
\end{abstract}

Y.-C. Liao · K.-T. Shao ( $ه)$

Biodiversity Research Center, Academia Sinica,

128 Academia Rd., Sec. 2, Nankang, Taipei

11529, Taiwan, ROC

e-mail: zoskt@gate.sinica.edu.tw

\section{L.-S. Chen}

Provisional Office, National Museum of Marine Science

$\&$ Technology, Keelung, Taiwan, ROC
Keywords Biological invasion - Marine introduction - Red drum - Sciaenops ocellatus . Human release $\cdot$ Religious release $\cdot$ Taiwan

\section{Introduction}

The accelerating rate of marine species invasion and the associated ecological impacts around the world have aroused much attention in recent years (Cohen and Carlton 1998; Ruiz et al. 1997, 2000). The two mechanisms for biological invasions are natural population extensions and anthropological introductions (Carlton 1987, 1989). Human factors include ballast water transport (Baltz 1991; Carlton 1985; Carlton and Geller 1993; Moyle 1991; Wonham et al. 2000), marine culture (Friedlander et al. 2002; Randall 1987), the aquarium trade (Semmens et al. 2004), oil drilling platform transfer, fisheries development, species released for scientific research, and movement through canals (Carlton 1989). Marine fish introductions are mostly restricted to enclosed basins including inland seas, estuaries, and coastal bays (Baltz 1991; Grosholz et al. 2000; Taylor et al. 1984); or introduced species are anadromous (Taylor et al. 1984). Successful marine fish introductions are relatively rare and thought to have lower impacts on ecosystems than their terrestrial counterparts (Baltz 1991; Randall 1987). Nevertheless, two recent cases of marine invasion have caused concern since there is a lack of knowledge of their impacts on the 
local ecology. The first example is the Hawaii marine snapper, Lutijanus kasmira, which has become the second most abundant fish since its introduction to Hawaii to improve fisheries (Friedlander et al. 2002; Randall 1987). The second example is the Pacific lionfish, Pterois volitans/miles complex, which recently invaded the Atlantic coast of the southeastern US and appears to have become established there (Hare and Whitfield 2003; Kimball et al. 2004; RuizCarus et al. 2006; Semmens et al. 2004; Whitfield et al. 2002, 2007). Because the effects of marine fish invasion are difficult to measure, greater awareness of the impacts on the ecology is needed (Bax et al. 2001).

The Atlantic red drum, Sciaenops ocellatus, is a large marine fish that inhabits the Atlantic coast of the US from Long Island to Florida and the Gulf of Mexico from the west coast of Florida to at least Laguna Madre, Mexico. Adult fish dwell on sandy and sandy/muddy bottoms, and the fish enter estuaries when young. This species mainly feeds on crustaceans, mollusks, and other fishes. The maximum size is $160 \mathrm{~cm}$, and commonly reaches $100 \mathrm{~cm}$ (Chao 1995). It was first imported for aquaculture purposes by the Taiwan Fishery Research Institute in 1987. Since 1998, it has been sighted in the wild along the southwestern coast of Taiwan by anglers and reported on the local news (Chiu and Shao 2003). This has raised the following questions: has the red drum successfully invaded Taiwan?; and what were the mechanisms behind its invasion?

The importance of this report is that it documents the red drum as the first predatory marine fish from the Atlantic to invade the Indo-West Pacific. The distribution, potential survival, mechanisms of introduction, and possible ecological consequences of the red drum are discussed.

\section{Materials and methods}

Red drum sightings have been frequently reported, and fish have been collected by anglers and fishermen from western Taiwan since 1998; yet no voucher specimens were available until now. From February to June 2008, we requested, through local angler web sites (http:// www.agmz.com.tw/ and http://www.matsu.idv.tw/) for volunteers to provide red drum observations. Substantiated observations were mainly from photographs, news, and technique report (Wang 2002) since 2000. The specimens that we collected were photographed fresh before $10 \%$ formalin fixation and then transferred to $75 \%$ ethanol for permanent preservation. After that, the specimens were deposited in the Biodiversity Research Museum (formally the Research Museum of the Institute of Zoology, ASIZ), Biodiversity Research Center, Academia Sinica (BRCAS).

\section{Results and discussion}

The current distribution of red drums

There were 45 observations during the time span between March 2000 and June 2008, including 34 validated photographs, seven news sources, two collected specimens, and two technique report sources. The scattered distributions indicated that the red drum inhabits sandy and sandy/muddy bottoms along the western shores of Taiwan and around the Matsu Islands. Of the two specimens collected, one was from the impingement of the second nuclear power plant in northern Taiwan in April 2005 and the other was collected by gill net at Matsu in February 2008.

The red drum was first recorded on the southwestern coast of Taiwan; its range then extended northward to Changhua in west-central Taiwan (Chiu and Shao 2003). Our current records indicate that it has extended further northward to northern Taiwan and crossed the Taiwan Strait to Matsu (off the southeastern coast of Fujian Province, China). The records also show that the red drum prefers sandy and sandy/ muddy bottoms, or a sandy bottom with hard substrate (e.g., rocks in natural habitats, and concrete chunks in nearby harbors and peripheral embankments) along the sandy western shoreline of Taiwan and the adjacent continental shelf of China. These habitats are similar to its original natural habitats. There are no records from eastern Taiwan which is typically rocky or southern Taiwan where there are coral reefs. The substrate preference of this species has therefore restricted its distribution in Taiwan.

There are possibly two separate populations of red drums off western Taiwan; a larger population on the west coast of Taiwan and a smaller one found around Matsu. The separate distribution is possibly due to introductions from different sources. Since the red drum's introduction to China in 1995, there are 
reports of sightings from coastal provinces of China (Liao, unpublished data). It is believed that they escaped from net cages during typhoon Chebi in June 2001; however, there are no officially documented records. Further investigations along the coastal waters of China are warranted.

\section{Potential survival on the west coast of Taiwan}

The survival requirements for an invasive species include habitat preferences, food sources, temperature tolerance, and interactions with other species (Stauffer 1984). The invasive red drum has survived well in Taiwanese waters for several reasons. First, the habitats along western Taiwan are mostly sandy or sandy/muddy bottoms as found in its native areas. Second, the diet of red drums includes crustaceans, mollusks, and other fishes which are abundant around the west coast of Taiwan (http://coatbp.sinica.edu.tw/). Third, the temperature tolerance of red drums is $2-34^{\circ} \mathrm{C}$ while its optimal temperature is $12-30^{\circ} \mathrm{C}$ ( $\mathrm{Yu}$ 2000). Seawater temperatures along the Taiwanese coast range $7.2-35.5^{\circ} \mathrm{C}$ (http://www.cwb.gov.tw/), and are thus suitable for the red drum.

\section{Successful population establishment}

For an invasive species to be considered to have successfully established a population, the species needs to be documented as present and reproducing within the last 30 years; multiple records are required; and for species detected in the past 10 years, its occurrence is necessary in at least two localities or in two consecutive years (Ruiz et al. 2000). We believe the red drum has survived well and has successfully established populations in waters of western Taiwan and the Matsu Islands for the following reasons. First, the distributions and observations included all months for the time period between March 2000 and June 2008 and with multiple records in more than two localities for seven consecutive years (2002-2008). In addition, most body sizes (35 observations, 78\%) were larger than $60 \mathrm{~cm}$ TL and only five observations $(11 \%)$ were smaller. Since the red drum is usually reared and sold at about $30-50 \mathrm{~cm}$ TL (ca. 1-2 kg in body weight), the larger size shows that they have survived and grown nicely in the wild. Small-sized individuals may indicate the recruitment of young red drum, or they may be from other sources; but we lack histological evidence to verify its successful reproduction.

\section{Mechanisms for introduction}

Biological invasions can result from natural range extensions or human-induced introductions (Carlton 1987). The mechanisms of fish introductions by anthropological activities can be unintentional releases, deliberate introductions to improve fisheries, movement of fishes through canals, and the transportation by ballast water of ships (Baltz 1991). Our results show that the mechanisms for red drum invasion in Taiwan included deliberate releases to improve fisheries and for religious activities as well as escapees from aquaculture or marine net cages.

It is not likely that native Atlantic red drum was able to expand its natural range by moving westward through the Panama Canal, entering the East Pacific Ocean, and arriving at the West Pacific Ocean. Judging by the fact that there are no sightings of this species along the suspected route, the fish observed on the West Pacific Ocean are most likely exotic.

Ballast transportation is believed to be an important mechanism for the invasion of marine species (Baltz 1991; Carlton 1989; Carlton and Geller 1993; Wonham et al. 2000), and several cases of fish invasion have been reported (Baltz 1991; Carlton and Geller 1993; Randall 1987). Nonetheless, these invasive fishes were small in size such as members of the Blennidae and Gobiidae (Wonham et al. 2000). Nevertheless, since Kaohsiung Harbor in southwestern Taiwan is one of the most important international trade harbors worldwide (http://www.khb.gov.tw/), we cannot rule out this mechanism for the transportation of red drum larvae.

Escapees from aquaculture ponds. Heavy rainfall and high tides accompanying a typhoon often occur in southwestern Taiwan. They can cause floods and consequently allow fish to escape from high-density aquaculture ponds or marine net cages in these lowlying areas. This mechanism is suspected to be the cause of the red drum invasion, in both Taiwan and Matsu. Red drum is not a popular aquarium fish due to its large size, and it is only exhibited in a few aquarium shops. None of the aquariums has reported any escapees, thus making this invasion mechanism unlikely.

Invasions can be caused by releasing economic fish larvae around coastal waters for the purpose of 
improving fishery resources (Randall 1987). Before people became aware of the potential harm represented by marine exotic species, red drum could have been released, or it could have been mixed with other species that were released. Religious animal release is very popular in Taiwan (Severinghaus and Chi 1999); released marine culture fishes have included Japanese eel, grouper, sea bream, mullet, and red drum (Chen 2004). Our unpublished data denoted that the body sizes of released red drums were $<30 \mathrm{~cm}$, and about 15,000 individuals were released each time. However, the precise numbers and frequencies of releases for religious purposes are difficult to trace and document.

\section{Ecological consequences}

Exotic species can directly and indirectly change the density, distribution, growth characteristics, and behavior of one or more populations in a community. They have significant effects on many estuaries by fundamentally altering native populations, communities, and ecosystem processes (Ruiz et al. 1997). The ecological impacts of introduced fish in aquatic habitats include habitat alteration, introduction of parasites and diseases, trophic structure alterations, hybridization, and spatial alterations (Taylor et al. 1984). Furthermore, introducing fish to freshwater environments has been documented to cause the extinction of native species, as well as declines and displacement of native fish populations (Miller et al. 1989; Taylor et al. 1984). The impacts on marine habitats are less well documented. The two examples of marine invasive fishes are the snapper, Lutjanus kasmira, in Hawaii, and the Pacific lionfish, Pterois volitans/miles complex (Friedlander et al. 2002; Whitfield et al. 2007). The successfully established Hawaii snapper benefited from its characteristic of fast growth and a lack of competition in nearshore waters. It has become the second most abundant species in Hawaiian waters (Randall 1987). The reasons why the Pacific lionfish has recently become more abundant in the West Atlantic are that it has occupied new niches which opened up from the effects of overfishing of native species, has low fishery and low natural mortality, and has no competitor or predator along the Atlantic coast (Whitfield et al. 2007).
In recent years there has been serious problems with overfishing in Taiwan; as a result, the fish community has changed with a decrease of local species and their abundances (Liao et al. 2004). The vacant niches may be occupied by other species (Davis et al. 2000) and, in this case, by the more-competitive predatory red drum. Additionally, repeated releases of the fish increase the probability of its successful establishment of a population (Baltz 1991; Moyle 1985).

In conclusion, the Atlantic red drum was introduced into Taiwanese coastal waters. Our results indicate that the fish has survived well and probably is the third example of a marine fish invasion in the world. Still, we do not know its population dynamics in the wild, its interactions with other native species, or its ecological consequences in the community. As Elton (1958) mentioned, the history of introductions is a history of disasters that should not be forgotten. More caution, and awareness are called for on the part of the public, and in the future, target species for mariculture purposes should be native species, not exotic ones.

Acknowledgments We acknowledge Dr. Chiu-Ju Yao (Biodiversity Research Center, Academia Sinica) who collected the specimens, and all observers, anglers, and fishermen who contributed to the study. We also thank Ms. Lee-Sea Chen and Mr. Dan Chamberlin for manuscript proofreading.

Open Access This article is distributed under the terms of the Creative Commons Attribution Noncommercial License which permits any noncommercial use, distribution, and reproduction in any medium, provided the original author(s) and source are credited.

\section{References}

Baltz DM (1991) Introduced fishes in marine systems and inland seas. Biol Conserv 56:151-177

Bax N, Carlton JT, Mathews-Amos A, Haedrich RL, Howarth FG, Purcell JE, Rieser A, Gray A (2001) The control of biological invasions in the world's oceans. Conserv Biol 15:1234-1246

Carlton JT (1985) Trans-oceanic and interoceanic dispersal of coastal marine organisms-the biology of ballast water. Oceanogr Mar Biol 23:313-371

Carlton JT (1987) Patterns of transoceanic marine biological invasions in the Pacific Ocean. Bull Mar Sci 41:452-465

Carlton JT (1989) Mans role in changing the face of the oceanbiological invasions and implications for conservation of near-shore environments. Conserv Biol 3:265-273

Carlton JT, Geller JB (1993) Ecological roulette-the global transport of nonindigenous marine organisms. Science 261:78-82 
Chao NL (1995) Family Sciaenidae. In: Carpenter KE, Niem VH (eds) The FAO guide to species identification for use in the Central and Eastern Pacific fishery. vol 3: vertebrates-bony fishes (part 2). FAO, Rome, pp 1583-1653

Chen YM (2004) Investigation on living creatures released by religious groups from Taiwan. Environment and Animal Society of Taiwan, Taipei (in Chinese)

Chiu YW, Shao KT (2003) Status and management of marine invasive species. Conference for the Management of Invasive Species, Taipei, pp 103-110 (in Chinese)

Cohen AN, Carlton JT (1998) Accelerating invasion rate in a highly invaded estuary. Science 279:555-558

Davis MA, Grime JP, Thompson K (2000) Fluctuating resources in plant communities: a general theory of invasibility. J Ecol 88:528-534

Elton CS (1958) The ecology of invasions by animals and plants. University of Chicago Press, Chicago

Friedlander AM, Parrish JD, DeFelice RC (2002) Ecology of the introduced snapper Lutjanus kasmira (Forsskal) in the reef fish assemblage of a Hawaiian bay. J Fish Biol 60:28-48

Grosholz ED, Ruiz GM, Dean CA, Shirley KA, Maron JL, Connors PG (2000) The impacts of a nonindigenous marine predator in a California bay. Ecology 81:1206-1224

Hare JA, Whitfield PE (2003) An integrated assessment of the introduction of lionfish (Pterois volitans/miles complex) to the western Atlantic Ocean. NOAA Technical Memorandum NOS NCCOS 2: iiv, 1-21. NOAA, Washington, DC

Kimball ME, Miller JM, Whitfield PE, Hare JA (2004) Thermal tolerance and potential distribution of invasive lionfish (Pterois volitans/miles complex) on the east coast of the United States. Mar Ecol Prog Ser 283:269-278

Liao YC, Chen LS, Shao KT, Tu YY (2004) Temporal changes in fish assemblage from the impingement data at the second nuclear power plant, northern Taiwan. J Mar Sci Technol 12:411-417

Miller RR, Williams JD, Williams JE (1989) Extinctions of North American fishes during the past century. Fisheries 14:22-38

Moyle PB (1985) Exotic fishes and vacant niches. Environ Biol Fish 13:315-317

Moyle PB (1991) Ballast water introductions. Fisheries 16:4-6

Randall JE (1987) Introductions of marine fishes to the Hawaiian Islands. Bull Mar Sci 41:490-502

Ruiz GM, Carlton JT, Grosholz ED, Hines AH (1997) Global invasions of marine and estuarine habitats by non-indigenous species: mechanisms, extent, and consequences. Am Zool 37:621-632
Ruiz GM, Fofonoff PW, Carlton JT, Wonham MJ, Hines AH (2000) Invasion of coastal marine communities in North America: apparent patterns, processes, and biases. Annu Rev Ecol Syst 31:481-531

Ruiz-Carus R, Matheson RE, Roberts DE, Whitfield PE (2006) The western Pacific red lionfish, Pterois volitans (Scorpaenidae), in Florida: evidence for reproduction and parasitism in the first exotic marine fish established in state waters. Biol Conserv 128:384-390

Semmens BX, Buhle ER, Salomon AK, Pattengill-Semmens CV (2004) A hotspot of non-native marine fishes: evidence for the aquarium trade as an invasion pathway. Mar Ecol Prog Ser 266:239-244

Severinghaus LL, Chi L (1999) Prayer animal release in Taiwan. Biol Conserv 89:301-304

Stauffer JR Jr (1984) Colonization theory relative to introduced populations. In: Courtenay WR Jr, Stauffer JR Jr (eds) Distribution, biology and management of exotic fishes. Johns Hopkins University Press, Baltimore, MD and London, pp 8-21

Taylor JN, Courtenay WR Jr, McCann JA, Courtenay WR Jr, Stauffer JR Jr (1984) Known impacts of exotic fishes in the continental United States. In: Courtenay WR Jr, Stauffer JR Jr (eds) Distribution, biology and management of exotic fishes. Johns Hopkins University Press, Baltimore, MD and London, pp 322-373

Wang HC (2002) Estimating water qualities with fresh water indicator fishes in Nangkang, Kuya, Chungkang, Beigang, Jiangjyun, and Dangbou Rivers. Environmental analysis laboratory, environmental protection administration, Taipei, Taiwan. Available at DIALOG http://www.niea.gov. tw/analysis/protect/2002/2002-11.htm (in Chinese)

Whitfield PE, Gardner T, Vives SP, Gilligan MR, Courtenay WR, Ray GC, Hare JA (2002) Biological invasion of the Indo-Pacific lionfish Pterois volitans along the Atlantic coast of North America. Mar Ecol Prog Ser 235:289-297

Whitfield PE, Hare JA, David AW, Harter SL, Munoz RC, Addison CM (2007) Abundance estimates of the IndoPacific lionfish Pterois volitans/miles complex in the Western North Atlantic. Biol Invasions 9:53-64

Wonham MJ, Carlton JT, Ruiz GM, Smith LD (2000) Fish and ships: relating dispersal frequency to success in biological invasions. Mar Biol 136:1111-1121

Yu NH (2000) Red drum aquaculture. In: Aquaculture Larvae Monthly: 26. Fish Breeding Association of Taiwan, Taipei, Taiwan. Available at DIALOG. http://www.fish.org. tw/chinese/magazine/magazine-26f.htm (in Chinese) 